\title{
O LADO SOMBRIO DO CAMINHO: ESTUDOS CRÍTICOS EM ADMINISTRAÇÃO E RELAÇÕES PÚBLICAS CRÍTICAS
}

\section{Stephen Andrew Linstead ${ }^{1}$}

\section{Resumo}

Desastres financeiros e ambientais recentes têm instigado corporações a repensar suas estratégias em Relações Públicas (RP), assim especialistas em comunicações corporativas foram convocados para desenvolver um conjunto de estratégias de comunicação "pacificadoras" e não lidar apenas com definições de danos subsequentes a uma crise. Isso tem estimulado estudiosos e especialistas da área a dedicarem algumas reflexões críticas sobre as suas práticas. Contudo, até agora, a área emergente de Relações Públicas Críticas (RPC) tem sido marginalmente influenciada pelos Estudos Críticos em Administração (ECA), e o ECA tem dirigido pouca importância à RP. Este trabalho revisa as origens históricas de RP juntamente com o crescimento da ciência social crítica e revela significados consideráveis em linhas paralelas de desenvolvimento e de problemas de significação nas quais se encontram o bem social e os interesses corporativos. Este estudo trabalha com um exemplo conceitual que faz parte da inquietação do ECA - as relações entre desejo e poder - e analisa RP sob essa lente, focando no afamado caso de RP "Tochas da Liberdade" de Edward Bernays. Ao traçarmos a história de RP na ótica do desejo, somos levados a concluir que há muito em comum entre o ECA e a RP, embora raras conexões sejam feitas; que o ECA oferece um conjunto de instrumentos conceituais úteis para a RP, enquanto a RP torna disponível ao ECA um conjunto de narrativas negligenciadas; e já que o ECA e a RP se encontram questionando seus rumos futuros, eles podem usufruir do aprendizado mútuo, algo que eles ainda não conquistaram. Este trabalho conclui-se descrevendo como RP e ECA podem desenvolver linhas colaborativas de investigação ao empregar o critério triplo de Fournier e Grey: não-performatividade, desnaturalização e reflexividade.

1 The York Management School - University of York - Freboys Lane - Hestlington, York - Reino Unido. E-mail: stephen.linstead@york.ac.uk 
Volume 2 - Número 1 - Junho 2015

Palavras-chaves: Estudos Críticos em Administração; Relações Públicas; Poder; Psicanálise; História.

\title{
THE DARK SIDE OF THE OPEN ROAD: CRITICAL MANAGEMENT STUDIES AND CRITICAL PUBLIC RELATIONS
}

\begin{abstract}
Recent financial and environmental disasters have energised corporations to rethink their public relations strategies, and corporate communications specialists have been called upon to develop a range of "peace-time" communications strategies rather than retrospective damage limitation subsequent to a crisis. This has also stimulated scholars and practitioners in the field to engage in some critical reflection on their practices. Yet so far this emerging Critical Public Relations (CPR) has been only marginally influenced by Critical Management Studies (CMS), and CMS has given little attention to PR. This paper reviews the historical origins of PR alongside the rise of critical social science and reveals considerable resonances in their parallel lines of development and the struggles of meaning in which they engage between public good and corporate interests. The paper takes one conceptual example of a concern of CMS the connections of desire and power - and reads PR through this lens, focusing on the case of Edward Bernays celebrated PR coup "Torches of Freedom". Tracing the history of PR through desire leads us to conclude that there is much common ground covered by CMS and PR, although the connections are rarely made; that CMS offers a useful set of conceptual tools to PR, whilst PR opens out a neglected set of narratives to CMS; and that as both CMS and PR find themselves questioning their future direction, they may well learn from each other to an extent that they have not so far achieved. The paper concludes by outlining how PR and CMS might develop collaborative lines of inquiry deploying Fournier and Grey's threefold criteria of non-performativity, denaturalization and reflexivity.
\end{abstract}

Keywords: Critical Management Studies; Public Relations; Power; Psychoanalysis; History.

\section{EL LADO OSCURO DE LA RUTA: ESTUDIOS CRITICOS EN ADMINISTRACIÓN Y RELACIONES PUBLICA CRITICAS}

\section{Resumen}


Recientes desastres financieros y ambientales han instado a las empresas a replantear sus estrategias de Relaciones Públicas (PR) y especialistas en comunicaciones corporativas se convocaron para desarrollar un conjunto de estrategias de comunicación "constructores de paz" y no tratar sólo con ajustes de daños posteriores a una crisis. Esto ha alentado a los estudiosos y expertos en el campo de dedicar algunas reflexiones críticas sobre sus prácticas. Sin embargo, hasta el momento, el área emergente de Relaciones Públicas Críticos (RPC) ha sido ligeramente influenciado por estudios en Administración Crítico (CEPA) y la CEPA ha dirigido poca importancia a la RP. Este artículo revisa los orígenes históricos de RP, junto con el crecimiento de la ciencia social crítica y revela una considerable importancia en líneas paralelas de desarrollo y la importancia de los problemas que son el bien social y los intereses corporativos. En este estudio se trabaja con un ejemplo conceptual que es parte del cuidado ACE - la relación entre el deseo y el poder - y analiza RP en virtud de este objetivo, se centra en el famoso caso de la RP "Antorchas de la Libertad" Edward Bernays. Rastreando la historia de PR desde el punto de vista del deseo, nos lleva a concluir que no hay mucho en común entre la CEPA y el $\mathrm{RP}$, aunque se hacen conexiones raras; ACE ofrece una serie de herramientas útiles para la RP conceptual, RP esté disponible, mientras que el ACE descuidó un conjunto de cuentas; y puesto que la CEPA y el RP están cuestionando sus futuras direcciones, que pueden tomar ventaja de aprendizaje mutuo, algo que no han ganado. Este documento concluye describiendo cómo las relaciones públicas y la CEPA pueden desarrollar líneas de investigación en colaboración mediante el empleo de los criterios de triples de Fournier y Grey: no performatividad, desnaturalización y la reflexividad.

Palabras-clave: Estudios Críticos en Administración; Relaciones Públicas; Poder; Psicoanálisis; Historia.

\section{Introdução}

Publicidade é essencialmente uma questão de psicologia de massa. Nós devemos lembrar que as pessoas são guiadas mais pelos sentimentos do que pela mente... Psicologia de massa é um dos fatores importantes que motiva todo esse mercado (LEE, 1921 citado por EWEN, 1996, p. 132). 
"Bem-vindo ao lado sombrio" foi como o jornalista financeiro Tim Burt, recentemente indicado como consultor "estratégico de comunicações corporativas" da Brunswick, foi recepcionado pelo diretor financeiro da Reuters para uma discussão secreta do Conselho de Administração sobre um lance de $\$ 18$ bilhões de dólares feito à empresa pelo seu rival Bloomberg (BURT, 2012 p. vii). A partir da década de 1980, um novo ramo de Relações Públicas (RP) em finanças e negócios vem se desenvolvendo com o intuito de administrar a imagem e a reputação corporativa, especialmente no contexto de fusões e aquisições, para influenciar a formação de opinião e para conduzir relações em uma variedade de meios de comunicação que desde a revolução digital tem se tornado muito mais complexos, mais velozes na disseminação da informação (apesar da veracidade dessa informação), mais difícil de prever e mais tridimensional (BURT, 2012 p. xi). Ademais, crises administrativas estavam se tornando mais costumeiras do que ocorrências excepcionais, com Goldman Sachs, Toyota e BP vivas na memória do público em meados da crise financeira de 2008. A má abordagem do desastre de óleo da Deepwater Horizon no Golfo do México aumentou os níveis de ansiedade muito além da indústria petrolífera - ninguém gostaria de estar na posição da BP quando eles estavam com a "reputação exposta". Se a crise os acometesse, eles não gostariam que suas comunicações públicas a tornassem pior. No entanto, isto exigia estratégias extensivas e efetivas anticrise, ou "pacificadoras", de RP.

Há uma relação significativa aqui com as origens de RP no começo do século passado. Enquanto escrevo isto, já se faz cem anos desde o Massacre de Ludlow, no qual soldados da Guarda Nacional Colorado e oficiais de segurança da Companhia de Combustível e Ferro do Colorado atearam fogo ao acampamento de mineradores grevistas sindicais e suas famílias. Anteriormente a este fato, eles tinham sido expulsos das casas onde moravam, as quais eram propriedade da empresa. Os mineradores, preocupados, cavaram buracos debaixo das tendas para que suas famílias pudessem se proteger de balas perdidas: duas mulheres e onze crianças morreram sufocadas ou queimadas em uma única tenda, em um total de mortes que supera 26 pessoas (os relatos variam). A notavelmente insensível família Rockefeller era dona da empresa, cuidando do caso a partir do seu escritório John D. Rockefeller Jr. em Manhattan, onde foi forçada a não ignorar estes eventos. Eles contrataram Ivy Ledbetter Lee [citado anteriormente], um consultor de RP que tinha tido experiência com greves em outros lugares, para lidar com o dano na reputação da empresa no pós-crise. Este foi, provavelmente, o primeiro exemplo do que veio a se tornar uma ação comum, e também forneceu ao público evidências dramáticas para desconfiar de empresas "derivadas". Quando Lee, que foi um dos fundadores da RP, tentou divulgar o rumor de que o fogo tinha sido causado pelos grevistas ao virarem um fogão, ao invés de ter sido ocasionada pela companhia, e afirmou que a ativista sindical Mãe Jones de 


\section{O LADO SOMBRIO DO CAMINHO: ESTUDOS CRÍTICOS EM ADMINISTRAÇÃO E RELAÇÕES \\ PÚBLICAS CRÍTICAS \\ Stephen Andrew Linstead}

oitenta e dois anos era uma prostituta e responsável por uma casa de má reputação, foi batizado de "Venenoso Ivy" pelo novelista e ativista Upton Sinclair, uma alcunha que ficou (EWEN, 1996 p. 78-9).

Parece, então, que a relação da RP com o "lado sombrio", bem como sua incorporação por ela, é bem antiga, e que o recente surgimento de pesquisas acadêmicas que focam em iluminar o lado obscuro da administração e da organização - buscando expor o lado mais sombrio da governança corporativa - teria pouco em comum com isso (LINSTEAD; MARÉCHAL E GRIFFIN, 2014). Entretanto, RP surgiu no mesmo período em que as Ciências Sociais de Sociologia, Antropologia Social e Psicologia estavam se estabelecendo em um contexto de extensivas mudanças científicas, tecnológicas, econômicas, sociais, políticas, culturais e demográficas, as quais contribuíram para o surgimento da modernidade que era tanto sistêmica quanto simbólica, funcional e crítica - e que desafiou a "imutabilidade" cultural tradicional que tinha proporcionado à sociedade civil relativa estabilidade. Questionamentos sobre a relação entre a consciência individual e a viabilidade da democracia foram levantados e permanecem sem solução até os dias de hoje. RP e o pensamento social crítico viajaram através dessa história que se envolveu ativamente tanto com os avanços quanto com os problemas dos novos conhecimentos, das novas descobertas, e das novas tecnologias, e como os diferentes papeis dos diferentes setores da sociedade respondem a eles. Algumas vezes, os pontos de vista convergiam - RP podia manifestar tendências que eram ao mesmo tempo abertas e secretas, progressistas e reacionárias, cínicas e idealistas, manipuladoras e altruístas, elitistas e populistas.

Desde o seu início, RP tem lutado com aquelas dimensões características de sua ação que se estendem para além dos interesses específicos dos seus clientes imediatos, e mesmo com o seu surgimento para dominar os paradigmas funcionalista, instrumental e neo-científico de ambos os lados do Atlântico, tem existido aqueles que utilizam uma abordagem mais crítica, dialógica e relacional em se tratando de investigação comunicativa (L'ÉTANG, 2008 p. 254-255). L'Étang claramente resume as contribuições do crescimento da RP crítica nas últimas três décadas a qual teve um crescimento paralelo aos Estudos Críticos em Administração (ECA), embora pouco diálogo entre as duas áreas tenha existido. Com este trabalho, pretendo estimular uma troca mútua entre as duas áreas, primeiramente resumindo algumas das principais preocupações do ECA, em seguida observando como RP e o pensamento crítico se desenvolveram em relação aos debates fundamentais que, eu discuto, como sendo centrais na conceituação de desejo e sua relação com poder. Finalmente, identifico algumas áreas de interesse comum nas quais esses dois campos de estudos podem colaborar reciprocamente. 


\section{Estudos Críticos em Administração (ECA)}

ECA trata de um conjunto de abordagens heterodoxas no estudo de administração que coletivamente contestam pontos cegos, silêncios e supressões da teoria da administração clássica e dos métodos funcionalistas predominantes. Estes métodos desafiam a tendência convencional do pensamento administrativo para desistoricizar, dessexualizar, despolitizar, descontextualizar e subsocializar eventos - ou pelo menos tratar desses assuntos de forma restrita e truncada. Diversidade em teoria e prática é primordial, problemas globais e que perpassam culturas são considerados como um encontro entre ambos em vez de serem desafios que eles apresentam como formas de controle e incorporação. O meio ambiente ocasiona adaptação responsável em vez de ser visto como recurso de controle e exploração. Controle e resistência são problemas políticos que devem ser levados a sério em vez de apenas constituírem problemas técnicos a serem superados. Como expressa a missão da Divisão dos Estudos Críticos em Administração, ECA constitui em uma:

crítica às práticas administrativas antiéticas e da ordem social exploratória. Nossa premissa é que as características estruturais da sociedade contemporânea, tais como o imperativo da lucratividade, o patriarcado, a desigualdade racial e a irresponsabilidade ecológica, frequentemente tornam organizações instrumentos de dominação e exploração. Levados por um desejo comum de transformar essa situação, objetivamos, através de nossas pesquisas, ensino e prática, desenvolver interpretações críticas de administração e sociedade e gerar alternativas radicais. Nossa análise busca conectar falhas técnicas em gestão e em gerentes individuais com as demandas de um sistema socialmente perturbador e ecologicamente destrutivo dentro do qual os administradores trabalham.

A montagem do arco-íris, ou do emaranhado, de perspectivas dentro do ECA é uma tentativa de Alvesson, Bridgman e Willmott (2009) no Manual de Estudos Críticos em Administração (Handbook of Critical Management Studies). O trabalho é assustador, e as escolhas, embora amplamente representativas, são algumas vezes frustrantes. Perspectivas teóricas especificamente dirigidas são a Teoria Crítica (Escola de Frankfurt), o realismo crítico, o pós-estruturalismo e a Teoria do Processo de Trabalho. Teorias ausentes podem ser considerados como sendo a 
teoria institucional crítica (Bourdieu, surpreendentemente, é indexado apenas uma vez); a teoria do ator-rede (Latour aparece apenas três vezes); e apesar de Lacan e Žižek serem indexados cautelosamente, a psicanálise não o é, nem mesmo as abordagens críticas à estética e ao design. Além disso, conquanto o pós-estruturalismo seja discutido, o pós-modernismo é tratado en passant em pouco mais de um parágrafo, com Lyotard sendo citado apenas uma vez (apesar de haver um capítulo sobre Sistemas de Informação); Baudrillard, apesar de sua imensa contribuição à sociologia crítica do consumo, foi mencionado apenas três vezes, duas das quais ocorreu no capítulo destinado à metodologia, e Deleuze, com ou sem Guattari, apenas duas citações, apesar do seu inegável status como um gigante da crítica filosófica do capitalismo e sua influência massiva sobre Hardt e Negri, os quais também foram pouco representados.

Para darmos aos editores aquilo que lhes é devido, eles são limitados pela necessidade de propagar a literatura publicada naquele momento explicitamente alinhando-se a elas ou sendo identificados por outras publicações referentes ao ECA. Este conteúdo trata de publicações relevantes, de alguma forma desproporcionalmente, desde 2006, e que certamente não refletem tendências desde 2009. Ao dedicarmos nossa atenção especificamente às Relações Públicas, estas omissões emergem como infortúnios já que elas poderiam oferecer influência significativa ao surgimento das abordagens críticas de RP. Neste trabalho, eu pego algumas sugestões das críticas ausentes da "hetero-ortodoxia" que o Manual do ECA fornece ao focar minha atenção no conceito de desejo, e a maneira como ele tem sido repensado através do século XX desde Freud, via teoria crítica, Lacan e Deleuze, particularmente em relação à questão da ideologia. Faço conexões aqui às antigas contribuições à RP incluindo as de Edward L. Bernays, sobrinho de Freud, o qual era frequentemente visto como o mais bem sucedido produto da sua própria prática de RP. Bernays é constantemente tratado como um "fã" leigo e seguidor dos trabalhos do tio, mas reconsiderações do seu trabalho juntamente com o de seus contemporâneos podem ser instrutivos à luz de trabalhos mais recentes do ECA sobre "ideologia", identidade, e como um entendimento mais aprofundado das dinâmicas do desejo podem iluminar os trabalhos da imagem, do discurso, da retórica, da motivação, dos desejos e das necessidades de RP (cf, EWEN, 1996; Tye, 1998). Além disso, novos questionamentos em governança, ética, emancipação e autonomia são levantados em consonância com trabalhos recentes de RP Crítica.

\section{O Co-Surgimento de RP e as Ciências Sociais}

Muitos estudiosos do ECA, alheios à história da RP em ambos os lados do Atlântico, provavelmente se surpreenderiam ao descobrir a extensão com que os pioneiros de RP se engajaram com os desenvolvimentos da 
ciência social contemporânea. A curiosidade foi levada pela necessidade de desembalar as relações centrais entre os indivíduos, os grupos (particularmente elites), e, além disso, os grupos de massa, tais como multidões (ou bandos) que podem impor desafios para uma democracia social efetiva e para uma preservação da ordem cívica em tempos de mudança e, de fato, de conflitos de interesse (EWEN, 1996; Tye, 1998). O compromisso do Esclarecimento com a capacidade do indivíduo com o pensamento racional, e sua liberdade de exercê-lo, foi associado com a crença na exequibilidade e desejabilidade de um maior envolvimento das pessoas no processo democrático, com pesos iguais enquanto indivíduos. $\mathrm{Na}$ virada do século $\mathrm{XX}$, isto emergiu com a necessidade de educar e informar o público, a fim de fornecer "os fatos" sobre os quais deviam refletir racionalmente, e este foi o compromisso dos primeiros contribuidores de RP, incluindo o jornalista profissional Ivy Ledbetter Lee, nascido na Geórgia e educado em Princeton, bem como o jornalista intelectual educado em Harvard, Walter Lippman. Entretanto, nos anos de 1920, uma mudança ocorreu - o ex-socialista Lippman rapidamente se tornava um defensor elitista, e as preocupações sobre as divergências entre o público potencialmente educável e racional e as emoções e imagens foram expostas, abalando a multidão. Entre os dois, a questão era se a multidão sentimental poderia ser dominada pela elite manipuladora preparada para usar as descobertas da ciência e da ciência social na preservação (ou aquisição) de poder e privilégio, em um novo e reestabelecido sistema de ordem social. O papel da RP ou propaganda na primeira e segunda guerras mundiais foi tão significativo nessa discussão quanto foi o uso de suas técnicas pelos Nazistas em sua conquista de poder - supostamente incluindo, para sua surpresa e particularmente uma ironia atroz, o trabalho do judeu graduado em Cornell e sobrinho de Freud, Edward L. Bernays (TYE, 1998 p. 111; BERNAYS 1965 p. 652). O foco e os métodos de RP mudaram neste período, mas nenhum deles foi de forma brusca, já que as correntes que se desenvolviam eram baseadas em ideias já familiares da nova sociologia (Gabriel Tarde, Robert Ezra Park), da psicologia (Gustave Le Bon, Wilfred Trotter, Sigmund Freud) e do pensamento político (Graham Wallas).

$\mathrm{Na}$ Europa, contribuidores fundamentais para essas discussões foram o psicólogo Le Bon, um dos favoritos de Theodore Roosevelt, e o sociólogo Tarde (cujo trabalho visionário sobre o papel da mídia global e da virtualidade recentemente adquiriu o interesse de estudiosos como Bruno Latour [Latour e Lepinay 2010], e, dentro da comunidade do ECA, Barbara Czarniawska [2009]). O trabalho de Le Bon (1895) intitulado A Multidão: Um Estudo da Mente Popular (The Crowd: A Study of the Popular Mind) demonstrou o quanto a experiência da Comuna de Paris em 1870 afetou a segurança da classe média liberal, que era temerosa do desenvolvimento do socialismo no meio dos grupos trabalhadores com seu comportamento de "massa" (Elton Mayo, que se tornaria famoso como o pai dos Estudos 
de Hawthorne do comportamento humano no trabalho nas décadas de 1920 e 1930, foi similarmente afetado pelas turbulências industriais e políticas em Adelaide na virada do século [TRAHAIR, 2006 p. 28 - 42]).

Le Bon argumentava que havia uma diferença entre o público (classe média) capacitado do pensamento racional e a multidão (classe trabalhadora) que era levada pela emoção mais do que a razão e sendo incapazes de exercer esta última. Enquanto a lei da multidão ameaçava sobrepujar a lei da razão, Le Bon, em contrapartida, argumentava que mesmo entre os racionais "o papel do inconsciente em nossos atos é imenso... o papel da razão é muito pequeno" (LE BON, citado por EWEN, 1996 p. 133). O que era pior, analistas tinham só arranhado a superfície da investigação dos motivos inconscientes. A civilização, ao se constituir de uma ordem social rigorosa e hierárquica criada e imposta por uma elite superior, conseguiu manter o caos do instinto em cheque, mas o desenvolvimento da democracia, o declínio da religião e o despertar da consciência das classes trabalhadoras ameaçaram esta estabilidade. Le Bon argumentou que a multidão erradicou a personalidade individual, e que absorveu o indivíduo em algo maior do que eles próprios, no qual eles descartaram quaisquer capacidades racionais e éticas que tivessem em favor do popular ou da "mente coletiva". Em meio à massa, eles pensariam, sentiriam e atuariam diferentemente caso fossem fazê-los como indivíduos - a psicologia de grupo e a psicologia individual eram distintas.

Le Bon era pessimista em relação aos efeitos do comportamento de massa na sociedade. Contudo, ele entendia que esses efeitos poderiam ser mediados, se não controlados, por líderes que entendessem da psicologia de massa. Já seu amigo Tarde, em compensação, era mais otimista, mas muito além do seu tempo ao ver o social como um ser em vias de ser suplantado pelo novo público. Este público não estava conectado por uma proximidade física nem movido por uma contaminação emocional, como ocorria nas massas, mas por uma conexão espiritual e mental que era sustentada pela crescente mídia e pelo aparato da comunicação. A mídia até mesmo deu forma e padronizou os conteúdos das conversas diárias, já que "basta uma caneta para instigar um milhão de línguas" (TARDE, 1969 p. 313). A massa desordenada era o grupo social do passado, com a mídia de massa transformando o trabalho comunicativo de conversação em um discurso unificado de ordem maior, finalmente superando os conflitos. A visão de Tarde sobre a crescente comunidade virtual era talvez otimista demais, mas certamente antecipou os efeitos da televisão, do cinema e da internet. Similarmente, Hardt e Negri (2000) reconheceram os processos de informatização que eles veem como geradores das mudanças do final do século XX, entretanto eles argumentam que aonde as forças socioeconômicas globalizadoras criaram o que eles chamam de Império, isto não padroniza emoções e nem resolvem conflitos "públicos", mas geram uma resistência contrabalanceada do seu próprio desejo 
dominador, não pelo público, mas pela virtualmente constituída "multidão".

Robert Ezra Park, que depois iria liderar o crescimento da sociologia na Universidade de Chicago, abordou em A Multidão e o Público (The Crowd and the Public) (PARK, 1904) uma distinção similar entre a "mente do público" e a "mente da multidão", sendo a primeira crítica e racional, e a segunda simples, bruta e impulsiva. Contudo Park também se preocupava com os efeitos da mídia que tinham instigado Tarde. Para Park, a mídia estava tornando essa distinção cada vez menos discernível, tratando da opinião do público como um "impulso coletivo ingênuo... manipulado pelos slogans" ao invés de posição adquirida através de discussões sobre fatos (EWEN, 1996 p. 135). O teórico político britânico Graham Wallas (1908) enfatizou a noção errônea de pensamento na qual a ação era intelectualmente moldada e formada por indivíduos que primeiro pensaram o desejo final, e assim calcularam as melhores maneiras de atingi-lo (EWEN, 1996 p. 136). Inferências inconscientes irracionais vieram primeiro e, assim, a arte da política era descobrir como explorá-las.

Outro pensador equipotente e influente foi Wilfred Trotter (1916), que reafirmou a importância da compreensão das forças instintivas ou do "instinto do bando" que guiavam as relações humanas. Trotter viu essa força como originadas do vazio, um "senso de incompletude o qual compele o indivíduo a buscar, em uma existência muito maior que a sua própria, algum ser em quem suas perplexidades pudessem encontrar a solução e a paz almejada" (TROTTER, 1916, citado por EWEN, 1996 p. 137). A visão de Trotter em relação ao desejo antecipa, aqui, a discussão da imago organizacional de Howard Schwartz, no qual ele afirmou ter sido o sucesso das iniciativas culturais corporativas dos anos 1980, e simultaneamente a causa de suas muitas falhas desastrosas (SCHWARTZ, 1992). Entretanto Trotter parte da distinção entre o indivíduo e o grupo encontrada em Le Bon, em que o grupo é visto como a base na qual as ansiedades do indivíduo são trabalhadas.

No período do pós-guerra e com a ajuda de seu sobrinho Bernays para publicar seu trabalho nos Estados Unidos, Sigmund Freud se tornou mais influente. Seu impacto em RP foi bastante considerável com o resultado do seu livro de 1922, Psicologia das Massas e a Análise do Eu (Group Psychology and the Analysis of the Ego), no qual, ao demonstrar um imenso respeito por Le Bon, apontou seu trabalho "brilhantemente executado" e evidenciou ponto a ponto que o indivíduo e o grupo eram inseparáveis e mutuamente determinantes. Um indivíduo podia influenciar o grupo através da psicologia individual, e o indivíduo pode ser influenciado através de processos de grupo e de implicação da massa. A preponderância da fantasia e da ilusão emergindo de desejos não realizados foi notada por Freud, o qual concordou com Le Bon que a massa pensa através de imagens ao invés de ideias, mas afirmou que isto também era verdade em se tratando de indivíduos encorajados à associação livre. As imagens eram 
a chave para o estímulo da imaginação da massa, promovendo um estado paralelo de hipnose em massa ao alimentar a fome dela por ilusão.

Walter Lippman se apoderou da ideia de compreensão através das "imagens em nossa cabeça" ainda mais além ao argumentar sobre a criação de uma pseudo-realidade que disciplinaria a "agitada e florescente confusão" do mundo externo. Pseudo-ambientes simbólicos funcionam através de associações estereotípicas que tornam fáceis os processos de interpretação de eventos e de relações complexas a partir da visualização e da dramatização. Imagens, fotografias e, cada vez mais, a produção hollywoodiana tem incomparável poder em agrupar indivíduos, deslocando as necessidades de um pensamento consciente ao ativar as emoções. Eles poderiam criar em um público disperso um "desejo homogêneo a partir de desejos de massa heterogêneos... uma intensificação de sentimento [com] uma degradação de significância" (LIPPMANN, 1928 p. 37-38). Por volta de 1928, Lippman estava reconhecendo que o público era uma criação virtual completa da mídia um fantasma. Na década de 1990, Jean Baudrillard (1994) levou esse argumento mais além, no contexto de uma mídia mais rica e de tecnologias comunicativas mais poderosas para defender que a fantasia tinha se tornado mais real do que o real - tinha se tornado hiper-real. Não era mais possível separar a imagem da realidade - uma compreensão que a própria Hollywood tomou emprestado no filme Matrix. O apetite do público for ilusão e o jeito fácil que estimulava a satisfação de desejos não realizados através da fantasia garantiu que enquanto a elite de Lippman continuasse provendo a pílula azul da hiper-realidade, não se buscaria a dolorosa pílula vermelha da realidade.

\section{Desejo e Crítica}

Além da importância das primeiras contribuições à psicologia da RP, o conceito de desejo é um dos mais importantes da filosofia do século XX, embora sua presença seja constantemente implícita. Michel Foucault, por exemplo, reservou o uso explícito do termo para o desejo sexual, embora muito do seu trabalho se fundamente no entendimento do desejo como sendo produzido discursivamente como uma falta, percebida pelo sujeito, de um elemento de determinado valor em um nexo de relações discursivas da linguagem, do reconhecimento institucional, do acesso ao conhecimento e das relações de poder. Compreensões de desejo tendem a cair em duas grandes visões: uma que podemos chamar de Hegeliana, a qual percebe o desejo como um caminho transitivo em direção ao objeto com o intuito de resolver a carência percebida, e outra que podemos chamar de Nietzschiana, na qual o desejo é visto como um caminho intransitivo, um movimento autônomo desprovido de seu objeto e que pode tomar diversos rumos. Para Hegel, o desejo é algo paradoxal, pois ao desejar sua própria satisfação, deseja, assim, a sua própria morte - uma 
charada que perpassa com relevância a RP no desejo do objeto em pertencer a um grupo, o qual necessita submergir da individualidade. Isto produz uma dinâmica na qual há um movimento dialético entre o eu e o outro. Para Hegel, o sujeito primeiro deseja o outro, ao querer ter o seu conhecimento, o qual difere daquele conhecimento do sujeito primeiro. E ao reconhecer o outro como outro, emerge-se uma necessidade recíproca no sujeito que é ser reconhecido pelo outro - então o desejo para o outro, o qual não pode ser totalmente alcançado, se torna o desejo para o seu reconhecimento a partir do outro, o que seria uma validação de seu valor. Em uma interpretação desenvolvida por Alexander Kojève, o desejo do sujeito não cessa nesse momento, mas torna-se um desejo de reciprocidade - isto é, não é suficiente ser reconhecido pelo outro, mas para o desejo do outro ser reconhecido pelo sujeito também é necessário este ser percebido. Desejo não é o desejo pelo outro, mas o desejo de ser desejado pelo outro.

A partir de Kant, no entanto, dois entendimentos adicionais surgem: primeiro, é que há sempre um elemento do outro que é radical, o qual não conseguimos entender porque é irredutivelmente outro. O segundo é que, a fim de relacionar completamente ao outro, deve haver elementos que não sejam radicais, que não sejam assimiláveis, mas que já sejam partes de nossa própria subjetividade. Como resultado, existe um outro, ou uma alteridade, dentro de nós mesmos. Mas a consequência disso é que não podemos erradicar a possibilidade de uma alteridade interior radical, uma parte de nós mesmos que é outro, o qual não podemos conhecer a não ser que, e até que, ele venha à tona dialeticamente. Juntamente com o desejo, então, é a ansiedade ontológica que resulta dessa situação. Relações com outros, e consequentemente relações em público, são motivados por uma combinação de desejo e ansiedade. $\mathrm{O}$ controle dos meios de estímulo do desejo e da redução de ansiedade e de um meio mais orgânico de manutenção da ordem social ao invés de repressão e supressão, recompensa e punição, é possível.

Dentro desse esquema, o desejo emerge como um caminho para se resolver uma carência percebida e experimentada, e esta compreensão básica como deficiência foi levada ao pensamento de Freud. Freud, através da psicanálise, desenvolveu um entendimento sobre a defesa do Ego, o qual nos protege da ansiedade, e sobre a catexia, na qual o desejo de um objeto inalcançável é deslocado para um objeto diferente. Os mecanismos podem ser complexos e intrigantes, mas acrescentam ao entendimento que, como analista, o que você conquista geralmente não é o que você deveria estar buscando. O que todas essas abordagens enfatizam é que o sujeito é insuficiente... deficiente de algo que falta para completar seu ser.

Uma rota alternativa não dialética, que vê o desejo como algo que transborda ao se tornar ao invés de um ser insuficiente, pode ser encontrado nos trabalhos de Nietzsche e de Bergson, emergindo poderosamente no pensamento multidisciplinar de Georges Bataille da década de 1930. Para Bataille (1988), o desejo era uma força poderosa que 
não se iniciava a partir da percepção de insuficiência - era um fluir da vida que era exuberante, levado ao excesso, para explorar e exceder seu potencial, surgindo do interior ao invés de algo que penetrasse ansiosamente do exterior. Esta compreensão também informa o pensamento de Gilles Deleuze e Felix Guattari, os quais substituem o movimento dialético histórico pelo rizoma multidimensional. Desejo é mais uma possibilidade do que uma falta; é mais potencial do que restrição. Abordagens freudianas nos conduzem a forças subjacentes existentes atrás de mecanismos mascarados, através dos quais o desejo pode ser apresentado, e que nos ensina que os objetos podem ser apresentados ao capturar aquelas forças subjacentes porque elas são inconscientes e catexizadas. Foucault, embora não use esses termos, argumenta que, em efeito, viu o desejo não em termos de insuficiência ontológica oculto às suas manifestações, mas como sendo criado ou manufaturado pelas formações discursivas (como a linguagem) resultantes de operações de poder e conhecimento. Deleuze e Guattari (1984; 1987) restabelecem o desejo ontologicamente, mas não como carência precisando ser satisfeita: para eles a linguagem e outras representações simbólicas não criam o movimento do desejo, mas atem seu fluxo, temporariamente desviando-o.

Finalmente, em um período crucial que se estende de 1920 a 1950 (e nos casos de Habermas e Gadamer) a Teoria Crítica vinculou o trabalho de Freud com o de Marx a fim de ressuscitar a noção de ideologia de Marx como a base fundamental da crítica do capitalismo. Para Marx, o capitalismo era envolto por contradições que produziam desigualdades ainda maiores já que os valores tinham sido extraídos do sistema, gerando uma competição e crescimento acirrados. Para aqueles que pouco se beneficiaram do sistema continuar participando dele, coerção era sempre uma opção (como visto no Massacre de Ludlow), mas o que era preferível era a estrutura simbólica, tal como o sistema de crença, que cegava os trabalhadores à sua exploração e comodificação e poderia até fazê-los desejar toda essa situação. Esta era uma tarefa que poderia ser realizada pela religião, notavelmente condenada por Marx como o ópio das massas, mas de forma mais ampla foi denominada a ideologia. A ideologia era mais efetiva quanto mais fosse subestimada, naturalizada e aceita como inevitavelmente as coisas eram. A conformidade e o consentimento se tornaram inconscientes, a resistência não era considerada relevante, ao menos que houvesse consciência.

Os membros da Escola de Frankfurt, notavelmente Walther Benjamim, Theodore Adorno e Max Horkheimer, examinaram a sociedade de produção e consumo de massa, que tinha aumentado desde Marx, juntamente com um relativo declínio da religião organizada e o crescimento da cultura midiática, e argumentaram que a ideologia não era mais localizada em sistemas de crença como prontamente identificada na Ética Protestante. Para eles, a ideologia estava inserida em tudo o que 
estimulava o desejo de objetos específicos que poderiam ser consumidos; símbolos de status sociais específicos que indicavam tanto reconhecimento quanto pertencimento; e produtos culturais que produziam sentimentos (ao invés de emoções) que confortavam a ansiedade humana, nos trazendo de volta a uma agradável imagem do que éramos (até mesmo através da tragédia). Adorno (1980) chamou isso de Kitsch, embora o termo tenha sido usado desde a metade do século XIX. A finalidade da mídia de massa, canalizando Freud, era estimular os desejos inconscientes por produtos enquanto gerava-se um kitsch sentimental, confortando nossas ansiedades e reforçando nosso senso de quem éramos e o quê éramos. Estes eram os trabalhos da ideologia. A finalidade da teoria crítica, ao canalizar uma versão moderna de Marx e, mesmo que um pouco diferentemente, Freud, era a ideologia crítica - a exposição de um processo de "doping" cultural e a elevação da consciência. Isto, obviamente, como a psicanálise, não era algo necessariamente direto.

\section{Tochas da Liberdade ou Sinais de Submissão?}

Žižek (1989; 1997) toma o reconhecimento de Lacan da similaridade entre o tratamento de Marx em relação ao fetichismo da mercadoria e a análise de Freud em relação ao "sintoma". A ideologia se encontra na fantasia, e como ela é articulada materialmente, revela as tensões entre sua fantasia, sua realidade (que ocasiona a necessidade de articulação) e o que Lacan chama de o Real - o elemento ou excesso que não pode ser representado, contra os quais todas as formas de sistema representacional inevitavelmente falham, e ambas as ocasiões ou buscam representação ou são excluídas de algumas formas de obrigação à fantasia (o que o kitsch faz facilmente, por exemplo). O que está por detrás da fantasia é a tensão entre o que Lacan chama de Lei e sua transgressão. Poderíamos ilustrar isso ao considerarmos um dos mais famosos "eventos" da RP já ocorridos - a manifestação “Tochas da Liberdade" de Edward Bernays na Quinta Avenida de Nova Iorque durante a parada de Páscoa em 31 de Março de 1929, onde mulheres paravam em um lugar previamente combinado para acender seus cigarros Lucky Strike (TYE, 1998 p. 28-35). O patrocinador de Bernays, cuja identidade fora meticulosamente preservada, era a American Tobacco. Naquela época, fumar era algo aceito para as mulheres (SCHUDSON, 1984 p. 186-187, citado em TYE, 1998 p. 34), mas não necessariamente aprovado, e, assim, permaneceu o preconceito contra as mulheres que fumavam em lugares públicos. Bernays consultou o psicanalista A. A. Brill e, incentivado pelo seu conselho, foi capaz de persuadir um grupo de jovens mulheres elegantes e intelectuais de que isso era uma barreira à liberdade. Elas iriam, ao acender o cigarro em público, demonstrar sua independência, tanto como consumidoras quanto como pessoas. Bernays não iria somente incitar um mercado específico em relação aos produtos do seu patrocinador, mas também iria estimular o 
envolvimento entre consumo e identidade o qual foi se tornando cada vez mais importante nas propagandas desde então.

O conselho de Brill ao sobrinho de Freud foi que era normal para mulheres desejarem fumar, já que

a emancipação feminina tinha suprimido muitos dos desejos femininos. Muitas mulheres agora fazem os mesmos trabalhos que os homens. Muitas mulheres não têm crianças; e aquelas que desejam ter, têm menos filhos. A personalidade feminina está mascarada. Cigarros, ao serem associados com homens, tornam-se as tochas da liberdade (BERNAYS, 1965 p. 38).

Bernays ficou encantado com a justificativa de Brill, e sua metáfora, embora Brill posteriormente afirmasse que mulheres não deveriam oferecer cigarro aos homens, uma vez que "o cigarro é um símbolo fálico, o qual deveria ser oferecido à mulher pelo homem. Todo homem ou mulher normal podem se identificar com essa mensagem" (BERNAYS, 1965 p.395). Esta é mais do que uma simples convenção social: em aceitar o cigarro, o recebedor aceita o que Lacan denominou de "ordem fálica".

Em Lacan, o terreno psicológico de consciência e inconsciência é entendido em termos de relações feitas entre três domínios: o Imaginário, o Simbólico, e o Real. O Imaginário consiste no senso de coerência e plenitude que tornam a ideia do eu significativa, e surge a partir da Fase do Espelho que ocorre quando um infante vê sua própria imagem refletida de volta para ele. O Simbólico começa no início da linguagem, um sistema simbólico pré-fornecido, mas que também é aberto e está em constante mudança - aqui a criança aprende quem é dentro do sistema dos outros, distinto da coerência do seu próprio mundo imaginário. O Real é o que escapa de representação adequada na linguagem, aqueles elementos de significado que permanecem externos e elusivos, mas necessários para serem compreendidos. O simbólico pode fechar o caminho à coerência, ou pode prover um outro caminho, ou pode levá-lo em direção a um real inarticulado (por exemplo a arte). Dessa forma, a mídia é fundamental para influenciar a formação do sujeito. Žižek (1997) é novamente útil, já que a mídia não fornece simplesmente canais para o desejo, mas ela molda o próprio desejo em si: A fantasia está entre a estrutura simbólica formal e a positividade do objeto que encontramos na realidade... ela fornece um esquema de acordo com os objetos positivos em realidade que podem servir como objetos de desejo... fantasia não significa que quando eu desejo um bolo de morango e não consigo tê-lo em realidade, eu fantasio comendo o bolo; o problema é: como eu sei de início que eu desejo o bolo de morango? Isto é o que a fantasia me diz.

Ao vermos o evento de Bernays a partir dessa perspectiva, podemos perceber que a explicação simples da canalização sexual é inadequada, e a 


\section{O LADO SOMBRIO DO CAMINHO: ESTUDOS CRÍTICOS EM ADMINISTRAÇÃO E RELAÇÕES PÚBLICAS CRÍTICAS \\ Stephen Andrew Linstead}

relação com a liberdade é facilmente feita. Para Lacan, o desejo pela coerência que resulta da ausência fundamental na disposição feminina como sujeito é o imaginário em trabalho - o desejo por igualdade e liberdade é o desejo de equilíbrio e coerência. Entretanto, o sistema simbólico de ordem e lei restringe o feminino a uma posição subordinada. Incapaz e relutante em confrontar a Lei diretamente, o implícito Real de poder, o sujeito feminino aqui busca associações com os símbolos que possuem ou controlam a Lei. A Lei é fálica (entendida em termos de poder ao invés de sexualidade) e os símbolos do fálico podem ser transgressivamente colonizados - facilmente estabelecidos onde eles são transformados em produtos - e, assim, o sentimento irrequieto de falta é confortavelmente mitigado. A representação de Bernays criou a fantasia na qual o desejo por coerência e equilíbrio se tornaram o desejo pelo cigarro Lucky Strikes ao invés do desejo pelo bolo de morango. O gosto, em ambos os casos, não teria sido nem o amargo do cigarro nem o doce do morango - mas seria a novidade da liberdade. Kitsch funciona similarmente ao fornecer soluções pré-estabelecidas e facilmente acessíveis - estabelecendo associações sentimentais simbólicas que temporariamente aparecem para satisfazer o desejo por plenitude, por conexão emocional, por significância, por finalidade e por pertencimento a uma comunidade.

\section{Comunicação aberta e Vias Indiretas: Escondendo a Luz}

Com uma visão um pouco diferente de desejo, os sujeitos de Bernays, a partir de sua própria visão, já eram formadas, inteligentes, ativas, e imaginativas, e a participação na parada foi um meio de canalizar sua exuberância, embora estivessem ainda muito inseridas em um modelo patriarcal de entretenimento social. A cristalização de Bernays em relação às aspirações delas por expressão em uma direção particular transgressora contra um grão social não criou uma força, nem elas foram exclusivamente levadas através de um senso de falta. De fato, a percepção delas mesmas como sujeitos fragmentados contra um senso de coerência imposto anteriormente estava irrequieta com a sua participação no evento em si. Bernays, como era de costume, ponderou a informação comercial que ele forneceu, e este passo teve êxito porque o movimento social já tinha o seu próprio ímpeto. Bernays brevemente, e parcialmente, capturou o potencial rizômico das mulheres.

Obviamente, Lacan nos advertiria que a "liberdade" permaneceu intocada, exceto a nível simbólico, e embora o fato de as mulheres fumarem em público aumentasse a venda de cigarros, isso causaria um impacto mínimo na condição social delas. Bernays estava satisfeito com aquilo já que era o objetivo do seu cliente, uma vez que a abordagem de $\mathrm{RP}$ sempre optou pelo caminho indireto a fim de atingir finalidades sociais mais amplas que frequentemente provaram mais bem sucedidas para os objetivos de clientes específicos no longo prazo. Argumentos similares 
foram feitos por Chia e Holt (2009) em relação à "eficácia silenciosa da ação indireta" em estratégias corporativas. Até aqui, o lado negro foi que Bernays, durante todo o período de trabalho para a indústria de cigarro, estava divulgando informações sobre os efeitos negativos do fumo para a saúde, e seus empregadores tinham conhecimento desses perigos conhecimento suficiente para suprimir e até mesmo agir em descrédito ou imporem dúvidas relacionadas à veracidade das pesquisas.

Em se tratando da relação entre o simbólico e o real inexpressível, Bataille registrou uma diferença entre economia restrita (o campo da produção baseado em economia) e a economia geral (um campo simbólico e essencialmente moral). Ao entender-se o último, o qual era o projeto da humanidade em particular, exigia-se reconhecimento dos riscos envolvidos ao endereçar elementos de experiência e de "conhecimento" (ele usou o termo "não-conhecimento" - "non-knowledge") que foram sentidos ou percebidos embora tenha sido além da representação, um regime que ele denominou "sagrado". O fato de se atingir estados que permitem a alguns ter uma visão que vá mais além, frequentemente custam ao artista e ao filósofo sua saúde, sua sanidade e até mesmo sua vida, dada a natureza de um ciclo depressivo de trabalho intenso iniciado, dado que o espaço fora aberto para formas de arte mercadológicas e facilmente acessíveis - kitsch - que oferecem preencher o espaço da ansiedade, da angústia, do gozo e do êxtase com confortável sentimentalidade. Hollywood reconheceu esta forma desde o seu início, e à medida que a tecnologia se desenvolveu cada vez mais rapidamente permitindo efeitos mais complexos a serem reproduzidos em grande escala, como demonstrado por Benjamin (1968), o "real" inexpressivo se tornou algo deslocado pela sobrecarregada hiper-realidade informacional, a qual é dissecada por Baudriallard em seu último trabalho.

Em um nível mais acessível, Ritzer (2007) desenvolveu uma leitura, de certa forma, imparcial de Weber na tese de McDonaldização em relação à propagação da padronização de experiências e modos de produção da indústria de fast food para todos os aspectos das nossas vidas. Enquanto esse argumento crítico se deteve pouco em fontes mais radicais, em leituras mais radicais de Weber, ele também se baseou em elementos do trabalho de Baudrillard (1994, 1998) em consumo, no simbólico e na hiperrealidade ao examinar o "encantamento" que aproxima a "experiência econômica" à McDonaldização de produção e serviços (RITZER, 2010). A comunicação é de importância central aqui e os processos analisados são de importância fundamental para os estudos da mídia, propaganda, RP e ECA mais amplamente. Enquanto o trabalho de Baudrillard tem sido usado em ECA, ele não foi utilizado tão extensivamente quanto, talvez, deveria ser. (GRANDY; MILLS, 2004; HANCOCK, 1999).

Dois autores, cujos trabalhos se direcionam à natureza do desejo do espaço simbólico, sem discuti-los em termos de desejo, tem gerado uma sombra nas discussões de pós-modernidade nas três últimas décadas 
estando representados pelo debate entre Habermas VS Foucault. Brevemente, Habermas (1984) acredita que o projeto de iluminação à emancipação é inacabado, e essa comunicação sistematicamente distorcida, a qual funciona para legitimar a ideologia através da manipulação da racionalidade em nome dos interesses dominantes, é sua inimiga. A solução dele é identificar e remover condições limitadoras e estabelecer igualdade entre os falantes, extinguindo o mal-uso do poder e da dominação na "situação de discurso ideal".

RP pode encontrar um lugar em qualquer lado dessa trajetória, dependendo do estado de sua consciência. Para Foucault (2002), entretanto, conhecimento e poder estão inextricavelmente ligados neste complexo relacionamento o qual ele chama de "discurso". O discurso consiste, obviamente, em comunicação verbal, textual e em outros sinais, mas para Foucault qualquer discurso específico é também uma questão de relações entre conjuntos de declarações, ideias, atividades institucionais para comunicação e qualificação destas ideias, ações práticas, e o "efeitoverdade" naturalizado que derivam das realidades vividas como resultado da manipulação e monitoramente destes processos. Para ele, “a situação de discurso ideal" é uma fantasia acalorada que é outro produto do poder/conhecimento, e não há um senso de que a verdade está, ou possa estar "lá fora". Ele explicitamente rejeita o uso do termo ideologia, e ideologia crítica, porque isto implica a possibilidade de uma posição não ideológica da qual se lança tal crítica. As "verdades" da RP são, portanto, melhor categorizadas como efeitos das suas práticas de poder/conhecimento situado. O debate continua, mas há, entretanto, consideráveis áreas comuns de preocupação entre os dois. Foucault e Habermas tem seus próprios defensores dentro do ECA, embora questões nas margens da RP (comunicação em volta do tempo de fusão ou aquisição, por exemplo) tem ocorrido e a RP como campo, surpreendentemente, tem obtido uma atenção especial.

\section{Conclusões Críticas}

Em uma contribuição fundamental, Valerie Fournier e Chris Grey (FOURNIER; GREY, 2000) tentaram modelar o variado e disputado terreno do ECA, ao argumentar que havia três semelhanças perceptíveis entre os muitos esforços e oportunidades do compromisso que constitui o campo emergente. Muitos debates e argumentos se seguiram, e continuam, e leitores interessados poderiam consultar valiosamente uma variedade de fontes para completar esse quadro, incluindo Alvesson (2011), Alvesson e Willmott (2011), Banerjee (2007), Cox, Le TrentJones,Voronov e Weir, (2009), Fleming e Spicer (2007), Fournier e Grey (2000), Grey e Willmott (2005), Hancock e Tyler (2001), Jeanes e Huzzard (2014), Kelemen e Rumens (2008), Klikauer (2010), Linstead; Fulop e Lilley (2009), Parker (2002), Parker e Thomas (2011), Spicer, Alvesson, e 
Kärreman (2009) e Tadajewski; Maclaran; Parsons e Parker (2011). Para concluir, utilizarei a contribuição deles sobre a intenção não-perfomativa, a desnaturalização e a reflexividade para sugerir caminhos pelos quais as abordagens do ECA poderiam contribuir com o pensamento de RP.

\section{Intenção não-performativa}

A intenção performativa da corrente principal dos estudos de administração é óbvia, está fortemente comprometida em fazer com que as organizações funcionem melhor no que quer que seja (que elas acham) que fazem. Para a maioria das organizações servidas por Escolas de Negócios, isso significa fazer dinheiro, mas a administração também ocorre no campo da administração pública e no setor voluntário, embora todos possam apoiar mutuamente um sistema comum de consumidor e capitalismo financeiro. $\mathrm{O}$ uso performativo da métrica para medir atividades de curto prazo, ao invés de processos éticos, produz uma governabilidade que busca alinhar todos os setores. Fournier e Grey (2000) questionam o que as organizações fazem, ao invés de como elas fazem, como parte do ECA, o que envolve uma compreensão de como as coisas funcionam; identificando suas suposições e os sistemas políticos nos quais elas estão inseridas; avaliando suas consequências humanas, sociais e ambientais, e explorando alternativas. Deveria acrescentar-se, contudo, que a performatividade não é simplesmente uma questão de desempenho de tarefa, mas também de como aquele desempenho de tarefa também executa e exemplifica a identidade: quanto mais as escolas de negócio ajudam os negócios, mais elas se institucionalizam e se legitimam dentro do mundo dos negócios, enquanto ajudam a alinhar os interesses da sociedade com aqueles dos negócios. O ECA desafia esse processo.

\section{Desnaturalização}

Inextricavelmente ligadas ao trabalho performativo tradicional estão os métodos que se utiliza para vincular, estabelecer e propagar seu conhecimento e suas "verdades". Suposições sobre ontologia, epistemologia e métodos se tornam inquestionáveis e autossuficientes, constituindo um paradigma que reproduz uma maneira de ver a realidade como a ordem natural das coisas. Dentro dos estudos de administração tradicionais uma abordagem funcionalista permanece como modo predominante de investigação e análise, o que marginaliza outras abordagens e as obriga a adotar a ortodoxia canônica em seus próprios termos. O ECA diretamente expõe e contesta essas suposições que frequentemente são subestimadas.

\section{Reflexividade}


A pesquisa tradicional, geralmente, busca a objetividade além de eliminar o "viés" do modelo das ciências naturais. A reflexividade, se ocorrer, é algo superficial e se preocupa com erradicar os erros técnicos. Isto ignora o fato de que a investigação da ciência social nunca pode ser livre de valores, mesmo se no nível do pesquisador ou do sistema do patrocinador da pesquisa. O ECA aborda isso não simplesmente como uma questão de subjetividade pessoal que requer correção, mas como uma questão de subjetividade social e sistêmica que posiciona os pesquisadores, os sistemas de pesquisa, e o alvo da pesquisa dentro de regimes de poder e conhecimento e esferas de interesses e influências - ao ponto de delinear qual pesquisa é concebida além de como ela deverá ser conduzida. Para o ECA, essas questões são parte de um processo de pesquisa a ser abertamente discutido.

Em relação à RP, podemos pensar que é performativa por definição, auto-identificada como o negócio de "manufatura" (LIPPMAN, 1922) ou "engenharia" (BERNAYS, 1947) de consentimento. Não obstante considerar-se sua história, mostra-se que essa não foi sempre uma questão simples. Desde os primeiros dias, os praticantes refletiram sobre a natureza da disciplina de várias formas, às vezes vendo primordialmente como educacional e informativa, como um processo de duas vias, uma forma de mitigar os efeitos nocivos do rápido progresso social, ou de manipular as massas, ou de propagar a democracia, ou mesmo de facilitar um movimento para além das restrições tradicionais do social. A RP, ou propaganda, mediou algumas das grandes iniciativas sociais do século XX. Bernays (1994) promoveu o "capitalismo do bem estar" em 1944 e foi um crítico das políticas empregatícias da Companhia United Fruit na América Latina, preparando um plano de reforma em 1947, o qual foi adotado por eles em 1956 (TYE, 1998 p. 160-165). Contudo, Bernays também promoveu alguns dos grandes males do capitalismo como um agressivo assessor de imprensa reivindicando os interesses da Companhia United Fruit no começo da década de 1950, e por fortemente influenciar a percepção norte-americana da ameaça Comunista, levando a CIA a patrocinar uma invasão na Guatemala a qual derrubou seu governo (TYE, 1998 p. 172-176).

A partir da perspectiva do ECA, poderíamos questionar o que constitui o "público" e o bem público; qual seria a ética do "relacionamento" com esse público ou com seus setores específicos e até que ponto isso seria exploratório; aonde a compreensão profissional de RP como conselheira e consultora se posiciona em termos de regimes de poder/conhecimento de dominação e democracia; e até que ponto a RP como prática se orienta para além dos interesses do "cliente" específico e dos desejos atribuídos das suas percepções sobre os "públicos"? A história de RP com os Estados Unidos abarca o New Deal na década de 1930 (EWEN, 1996 p. 247-287); as estratégias de repercussão do “grande 
negócio" para marca de populismo de Roosevelt no final da década de 1930 e década de 1940 (EWEN, 1996 p. 306-336; MILLER; DINAN, 2008 p. 56-59); abarca também Ivy Lee e Carl Byoir separadamente aconselhando Hitler, Goebbels e os Nazistas na década de 1930 (MILLER; DINAN, 2008 p.18-20); a propagação das ideias econômicas de Reagan, o Reaganomics, e a circulação das ideias políticas de Margaret Thatcher, o Tchatcherismo, na década de 1980 (EWEN, 1996 P.394-397; MILLER; DINAN, 2008 p.100103); e um conjunto de empresas de RP aconselhando regimes envolvidos em atividades questionáveis na Zâmbia, na Rússia, no Egito PréPrimavera Árabe, em Bahrain, em Belarus e no Sri Lanka sobre "lavagem de reputação” (BURT, 2012 P. 106-108; MILLER; DINAN 2008 p. 78-124).

É bem claro que embora seja espetacular o crescimento da "circulação" e sua habilidade de se refazer em um contexto de "Império" globalizado (BANERJEE; LINSTEAD 2001; HARDT; NEGRI, 2000), mudanças na informação e na tecnologia de mídia, a possibilidade de movimentos sociais acessarem informações (ou dessas informações vazarem), a rápida comunicação e a digital organização estão gerando seus efeitos. Um deles é motivar a ideia de um público ou de uma "multitude" para além do social que pode contestar diretamente as influências das "elites", as quais coloca a questão de ideia performativa em cheque. Entretanto, como Miller e Dinan (2008 p. 78-98) demonstram, a existência de “elites" é real e palpável, e o neoliberalismo tem sido envolto pela RP já que Lippman influenciou Hayek na década de 1930 e a subsequente fundação da Sociedade Mont Pelerin com um objetivo de deteriorar a democracia em prol dos interesses corporativos (MILLER; DINAN, 2008 p. 63-65). Outro efeito é o questionamento de como se apresentam a "responsabilidade" em responsabilidade social corporativa (e as representações do tripé), o qual, como Bobby Banerjee (2007) conjectura, contém as iniciativas boas, as más e aquelas muito feias.

Desnaturalização pode parecer de novo que corre contra a força tradicional da RP, o qual buscava criar narrativas, ou mesmo eventos participativos nos quais trajetórias narrativas poderiam ser administradas, que fizessem ações ou iniciativas contestáveis parecerem confortáveis: razoáveis, naturais e até mesmo parecerem ser desenvolvimentos progressivos. Contudo, mais uma vez, a RP pode pelo menos parcialmente se redimir dos pontos de vista críticos por conta de sua abertura a descobertas científicas, sendo nas ciências sociais ou naturais. Há, obviamente, muitas evidências de RP sendo usada para suprimir ou distorcer as descobertas da ciência para enganar o público como Bernays fez quando trabalhava para a indústria de cigarro, mas Bernays guardou os arquivos originais e mais tarde fez campanhas contra a indústria, alcançando com sucesso a proibição de propaganda de cigarro no cinema e a inclusão de alertas de saúde nas carteiras de cigarro (TYE, 1998 p. 4750). O papel crítico potencial para RP aqui é enorme, porque desde a década de 1990 preocupações com mudanças climáticas e danos à 


\section{O LADO SOMBRIO DO CAMINHO: ESTUDOS CRÍTICOS EM ADMINISTRAÇÃO E RELAÇÕES PÚBLICAS CRÍTICAS \\ Stephen Andrew Linstead}

natureza tem se tornado um alarme real sobre os esforços de ambientalistas a fim de redirecionar, atrasar, desinformar e desacreditar as iniciativas ambientais responsáveis (FINEMAN, 2001; LAUFER, 2003; STAUBER; RAMPTON, 1995; RAMPTON; STAUBER, 2001). Uma influência do ECA em RP exploraria como os processos naturais se iniciam e resistem, e como a confiança pode ser construída através da não subestimação das coisas, incluindo não subestimar o próprio processo de comunicação. Muito da RP tem envolvido, e ainda envolve, personagens parecidos com aqueles do filme Zelig que se movem à beira da história levando consigo os eventos e criando impactos e seus efeitos sem ter que passar por processos tediosos de racionalização e justificação. Algumas vezes eles racionalizam informações e o acesso a elas, e, embora isso continue sendo possível, na era da internet é muito mais provável que a proliferação da informação e da desinformação crie uma desorientação no consumo. Um confuso consumidor - de ideias, de ideologias, de veículos, de candidatos políticos ou de fast food - tendem a reverter-se a uma rotina simples e frequentemente inconsciente para fazer sentido e fazer escolhas, como Bernays e seus colegas muito bem sabiam.

Reflexividade tem sido, tradicionalmente, um fenômeno no qual a RP explorou nos outros a criação de sua hiper-realidade e identidades de aspiração para o qual outros objetos são seduzidos a aspirar e adaptar-se. A RP em si, embora aparentemente se refletindo na sua própria identidade e princípios, e no caso de Bernays muito cuidadosamente em suas técnicas, parece historicamente ter se comprometido desde o começo. $\mathrm{O}$ que foi promovido não foi sempre praticado, a "neutralidade profissional" permitiu praticantes a ignorarem o estado de torpeza moral daqueles que eles davam conselhos e os efeitos dos conselhos a terceiros. Para o ECA, tais posições não são mais racionais: cada posição está imbricada com relações de poder, poder e conhecimento são inseparáveis, e manipulações da representação do conhecimento são intervenções políticas. Não é mais aceito nem possível evitar as consequências éticas daquelas posições e suas responsabilidades. Falar a verdade ao poder deve envolver um poder de encorajamento para falar a verdade aos que não tem poder. Os humanos podem ser pegos na teia de significação que eles mesmos criaram, mas "eles" não são todos iguais: os vetores de mídia que constituem uma matriz comunicativa não são o produto de uma democracia de fiandeiras, e por trás dessa teia muitas aranhas gigantes estão invisivelmente nas sombras à espreita. O ECA iria aconselhar a RP a abrir-se em relação às suas posições e responsabilidades nesse trabalho complexo e de influência entre o interesse pessoal e corporativo.

Retornando as considerações ao desejo, o ECA explicita a frequente conexão obscura entre fantasia psicológica, conhecimento e poder que a $\mathrm{RP}$ às vezes media e às vezes mascara. $\mathrm{O}$ desejo entendido como falta pode oferecer meios de controle e manipulação em escala de massa, ou através de aglomerações massivas de pessoas ou mesmo grandes massas 


\section{O LADO SOMBRIO DO CAMINHO: ESTUDOS CRÍTICOS EM ADMINISTRAÇÃO E RELAÇÕES PÚBLICAS CRÍTICAS \\ Stephen Andrew Linstead}

que são alcançadas pela mídia de massa e se rendem pela hiper-realidade. Entendida como uma força intransitiva de proliferação de energia, o desejo pode ser visto para ativar uma criatividade coletiva da "multidão" feita virtualmente interativa pela internet. Traçar a história da RP através do desejo nos leva a concluir que há muito em comum entre o ECA e a RP, embora as conexões sejam raramente feitas; o ECA oferece um conjunto de instrumentos conceituais úteis à $\mathrm{RP}$, enquanto a RP disponibiliza ao ECA aquelas narrativas negligenciadas; e se o ECA e a RP se encontrassem questionando suas direções futuras, eles poderiam aprender um com o outro a um nível que eles não atingiram até agora.

\section{Referências}

ADORNO, T. Bloch's 'Traces': The philosophy of kitsch. New Left Review, I/121, 1980. Online accessed November 152014 http:/ / newleftreview.org/I/121/theodor-adorno-bloch-s-traces-thephilosophy-of-kitsch

ALVESSON, M. Classics in critical management studies. Cheltenham, UK: Edward Elgar, 2011.

ALVESSON, M.; BRIDGMAN, T.; WILLMOTT, H. (Eds.). The Oxford handbook of critical management studies. Oxford, UK: Oxford University Press, 2009.

ALVESSON, M.; WILLMOTT, H. (Eds.). Critical management studies (Four-volume set). London, UK: Sage, 2011.

BANERJEE, S. B. 2007. Corporate social responsibility: The good, the bad and the ugly. Cheltenham, UK: Edward Elgar, 2007.

BANERJEE, S.; LINSTEAD, S. A. Globalization, multiculturalism and other fictions: The new colonization for the new millennium.

Organization, v. 8, n. 4, p., 711-750. 2001.

BATAILLE, G. The accursed share: An essay on general economy. Volume I: Consumption. London, UK: Zone Books, 1988.

BENJAMIN, W. The work of art in the age of mechanical reproduction. In H. Arendt (Ed.), Illuminations. London, UK: Fontana, 1968, p. 214-218.

BERNAYS, E. L.Crystallizing public opinion. New York, NY: IG Publishing, 1923/1961 
BERNAYS, E. L. Propaganda. New York, NY: IG Publishing, 1928/2005.

BERNAYS, E. L. Bernays on fear. TIDE March 7, p. 56, 1947a.

BERNAYS, E. L. Engineering of Consent Annals of the American Academy of Political Science 250(March), p. 113-120, 1947b.

BERNAYS, E. L. Biography of an idea: Memoirs of public relations counsel Edward L. Bernays. New York, NY: Simon and Schuster, 1965.

BORCH, C. Gabriel Tarde (1843-1904). In J. HELIN, T.; HERNES, D. HJORTH; R. HOLT (Eds.), The Oxford handbook of process philosophy. Oxford, UK: Oxford University Press, 2013, p. 185-201.

BURT, T. The dark art: The changing face of public relations. London, UK: Elliott and Thompson, 2012.

CHIA, R.; HOLT, R. Strategy without Design: The Silent Efficacy of Indirect Action Cambridge UK: Cambridge University Press, 2009.

COX, J. W.; LETRENT-JONES, T. G.; VORONOV, M.; WEIR, D. (Eds.). Critical management studies at work. Cheltenham, UK: Edward Elgar, 2009.

CZARNIAWSKA, B. Gabriel Tarde and organization theory. In P/ S. Adler (Ed.), The Oxford handbook of sociology and organization studies: Classical foundations. Oxford, UK: Oxford University Press, 2009, p. $246-67$.

DELEUZE, G.; GUATTARI, F. Anti-Oedipus: Capitalism and schizophrenia, Vol. 1 London, UK: Athlone, 1984.

DELEUZE, G.; GUATTARI, F. A thousand plateaus: Capitalism and schizophrenia, Vol. 2. London, UK: Athlone, 1987.

EWEN, S. PR! A social history of spin. New York, NY: Basic Books, 1996.

FINEMAN, S. Fashioning the environment. Organization. v.8, n. 1, p. 17-31, 2001.

FLEMING, P.; SPICER, A. Contesting the corporation: Struggle, power and resistance in organizations. Cambridge, UK: Cambridge University Press, 2007. 
O LADO SOMBRIO DO CAMINHO: ESTUDOS CRÍTICOS EM ADMINISTRAÇÃO E RELAÇÕES PÚBLICAS CRÍTICAS

Stephen Andrew Linstead

FOUCAULT, M. The archaeology of knowledge. London, UK: Routledge, 2002.

FOURNIER, V.; GREY, C. At the critical moment: Conditions and prospects for critical management studies. Human Relations, v. 53, n. 1, p. 7-32, 2000.

GRANDY, G.; MILLS, A. J. Strategy as simulacra? A radical reflexive look at the discipline and practice of strategy. Journal of Management Studies, v. 41, n. 7, p. 1153-1170, 2004.

GREY, C.; WILLMOTT, H. Critical management studies: A reader. Oxford, UK: Oxford University Press, 2005.

HABERMAS, J. The theory of communicative action: Reason and the rationalization of society. Boston, MA: Beacon Press, 1984.

HANCOCK, P. Baudrillard and the metaphysics of motivation: A reappraisal of corporate culturalism in the light of the work and ideas of Jean Baudrillard. Journal of Management Studies, v. 36, n. 2, p. 155-175, 1999.

HANCOCK, P.; TYLER, M. Work, postmodernism and organization: A critical introduction. London, UK: Sage, 2001.

HARDT, M.; NEGRI, A. Empire. Cambridge, MA: Harvard University Press, 2000.

HOBSBAWM, J. Where The truth lies: Trust and morality in the business of PR, journalism and communications. London, UK: Atlantic Books, 2010.

JEANES, E. ; HUZZARD, T. (Eds.) Critical management research. London, UK: Sage, 2014.

KELEMEN, M.; RUMENS, N. An introduction to critical management research. London, UK: Sage, 2008.

KLIKAUER, T. Critical management ethics. Basingstoke, UK: Palgrave Macmillan, 2010.

LATOUR, B.; LEPINAY, V. The science of passionate interests: An introduction to Gabriel Tarde's economic anthropology. Chicago, IL: University of Chicago Press, 2010. 


\section{O LADO SOMBRIO DO CAMINHO: ESTUDOS CRÍTICOS EM ADMINISTRAÇÃO E RELAÇÕES PÚBLICAS CRÍTICAS \\ Stephen Andrew Linstead}

LAUFER, W. S. Social accountability and corporate greenwashing. Journal of Business Ethics, v. 43, p. 253-61, 2003.

LE BON, G. The crowd: A study of the popular mind. Minneapolis, MN: Filiquarian Pulbishing, 1895/2005.

L'ÉTANG, J. Public relations: Concepts, practice and critique. London, UK: Sage, 2008.

LINSTEAD, S. A.; FULOP, L.; LILLEY, S. Management and organization: A critical text. Basingstoke, UK: Palgrave Macmillan, 2009.

LINSTEAD, S. A.; MARÉCHAL. G.; GRIFFIN, R. W. Theorizing and researching the dark side of organization. Organization Studies, v. 35, n. 2, p. 165-188, 2014.

LIPPMANN, W. Public opinion. Minnesota, MN: FQ Classics/Filiquarian Publishing, 1922/2007.

LIPPMANN, W. The phantom public. Piscataway, NJ: Transaction Publishers, 1925/2011.

MILLER, D.; DINAN, W. A century of spin: How public relations became the cutting edge of corporate power. London, UK: Pluto Press, 2008.

PARK, R. E. The crowd and the public. Chicago, IL: University of Chicago Press, 1904/1972.

PARKER, M. 2002. Against management: Organisation in the age of managerialism. Oxford, UK: Polity, 2002.

PARKER, M.; THOMAS, R. What is a critical journal? Organization, v. 18, n. 4, p. 419-427, 2011.

RAMPTON, S.; STAUBER, J. Trust us, we're experts! How industry manipulates science and gambles with your future. New York, NY: Tarcher/Putnam, 2001.

RITZER, G. Enchanting a disenchanted world: Continuity and change in the cathedrals of consumption (3rd. ed.). London, UK: Sage, 2010.

RITZER, G. The McDonaldization of society (5th. ed.). London, UK: Sage, 2007. 


\section{O LADO SOMBRIO DO CAMINHO: ESTUDOS CRÍTICOS EM ADMINISTRAÇÃO E RELAÇÕES PÚBLICAS CRÍTICAS \\ Stephen Andrew Linstead}

SCHWARTZ H. S. Narcissistic Process and Corporate Decay: The Theory of the Organizational Ideal. New York NY: New York University Press, 1992.

SPICER, A.; ALVESSON, M.; KÄRREMAN, D. Critical performativity: The unfinished business of critical management studies. Human Relations, v. 62, n. 4, p. 537-556, 2009.

STAUBER, J.; D RAMPTON, S. Toxic sludge is good for you! Lies, damn lies and the public relations industry. Monroe, ME: Common Courage Press, 1995.

TADAJEWSKI, M.; MACLARAN, P.; PARSONS, E.; PARKER, M. (Eds.). Key concepts in critical management studies. London, UK, Sage, 2011.

TARDE, G. The laws of imitation. New York, NY: Henry Holt, 1890/1903.

TARDE, G. On communication and social influence. In T. N. CLARK (Ed.), Gabriel Tarde on communication and social influence. Chicago, IL:

University of Chicago Press, 1969.

TRAHAIR, R. Elton Mayo: The Humanist Temper London UK:

Transaction Books, 2006.

TROTTER, W. The instincts of the herd in peace and war. London, UK: Keynes Press/ British Medical Association, 1916/1985.

TYE, L. The father of spin: Edward L Bernays and the birth of public relations. New York, NY: Henry Holt, 1998.

WALLAS, G. Human nature in politics. London, UK: A. Constable \& Co, 1908.

ŽIŽEK, S. The sublime object of ideology. London, UK: Verso, 1989.

ŽIŽEK, S. The plague of fantasies. London, UK: Verso, 1997. 